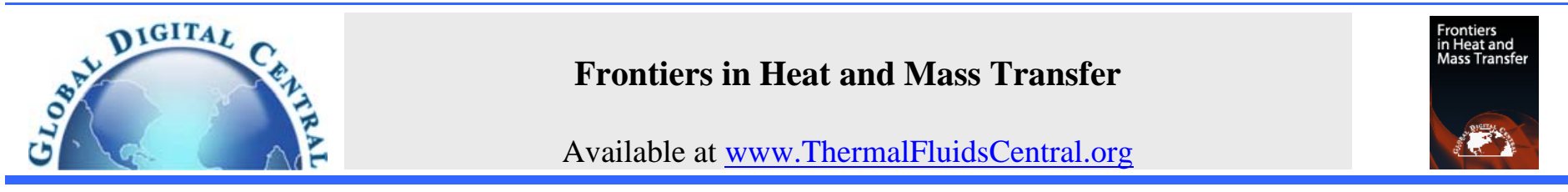

\title{
FREE CONVECTIVE HEAT TRANSFER OF MHD DISSIPATIVE CARREAU NANOFLUID FLOW OVER A STRETCHING SHEET
}

\author{
M. Sathish Kumar, N. Sandeep*, B. Rushi Kumar \\ Department of mathematics, VIT University, Vellore, 632014, India
}

\begin{abstract}
Nowadays external magnetic fields are capable of setting the thermal and physical properties of magnetic-nanofluids and regulate the flow and heat transfer characteristics. The strength of the applied magnetic field affects the thermal conductivity of magnetic nanofluids and makes it aeolotropic. With this incentive, we investigate the flow and heat transfer of electrically conducting liquid film flow of Carreau nanofluid over a stretching sheet by considering the aligned magnetic field in the presence of space and temperature dependent heat source/sink and viscous dissipation. For this study, we considered kerosene as the base fluid embedded with the silver (Ag) and copper $(\mathrm{Cu})$ nanoparticles. Numerical results are determined by employing Runge-Kutta and Newton's methods. Graphs are exhibited and explained for various parameters of interest. The influence of pertinent parameters on reduced Nusselt number, flow and heat transfer is discussed with the assistance of graphs and tables. It is found that thermal boundary layer of Ag-kerosene nanofluid is highly effective when compared with the Cu-kerosene nanofluid. It is also found that the thermal and momentum boundary layers of $\mathrm{Cu}$-kerosene and Ag-kerosene nanofluids are not uniform.

Keywords: MHD, Nanofluid, non-uniform heat source/sink, thermal radiation and free convection.
\end{abstract}

\section{INTRODUCTION}

Nanofluids are created an enormous interest over the past ten years due to its phenomenal properties and prospective applications. Many researchers have embraced recent uses of slurry made up of water and either silver or copper nanoparticles. Free convective heat transfer in thin film flow of nanofluids often encountered in many industrial and engineering disciplines. This application covers wire and fiber coating, heat exchangers, extrusion process, polymer processing and chemical processing equipment, etc. In the pioneering work of Chen (2003), who studied the power-law fluid film flow of unsteady heat transfer stretching sheet. An analytic solution for the momentum and heat transfer of liquid film flow over a stretching surface was explained by Wang (2006). Chen (2006) and Sajid et al. (2007) discussed the non-Newtonian thin film flow over an unsteady stretching surface taking into the account of viscous dissipation. And found that the fixed value of Prandtl number decreases with the thermal boundary layer.

Two-dimensional liquid film flow over an unsteady stretching sheet was numerically investigated by Dandapat et al. (2008). Heat and mass transfer in MHD non-Newtonian flow were numerically studied by Raju and Sandeep (2016). Dandapat et al. (2007, 2003) analyzed the effect of variable viscosity and thermo- capillarity on the heat transfer of liquid film flow over a stretching sheet. The micropolar film flow over an inclined plate, moving belt and vertical cylinder has numerically explained by Sajid et al. (2009). Dandapat and Chakraborty (2010) and Dandapat and Singh (2011) explained the thin film flow over a non-linear stretching surface with the effect of transverse magnetic field and observed that the raising values of viscosity parameter enhance the velocity field.

The researchers [Abel (2011), Khan et al. (2011), Liu and Megahad (2012), Liu et al. (2013), Vajaravelu et al. (2012)] analyzed the heat transfer characteristics of thin film flows by considering the different channels. Aziz et al. (2012) examined the effect of thermal radiation and thermocapillarity on the heat transfer thin film flow over a stretching surface. They observed that rising values of thermo capillarity enhances the velocity field. Tawade et al. (2016) presented the unsteady flow and heat transfer of thin film over a stretching surface in the presence of thermal radiation. The Eyring Powell flow and unsteady heat transfer of a laminar liquid film over a stretching sheet were studied by Khader and Megahed (2013) and found that increasing the Prandtl number reduces the temperature field across the thin film.

Anderson et al. (1992, 1996) studied the effect of a power-law fluid caused by thin liquid film on an unsteady stretching surface and found that effect of power-law index is more effective on temperature field. The liquid film flow over an unsteady horizontal stretching sheet was numerically discussed by Santra and Dandapat (2008). Noor and Hashim (2010) investigated the effect of magnetic field and thermocapillarity on an unsteady flow of a liquid film over a stretching sheet. Lin et al. (2015) explained the effect of MHD pseudo-plastic nanofluid flow and heat transfer film flow over a stretching sheet and concluded that raising the value of Hartmann number reduced the velocity profiles.

The study of non-Newtonian fluids has many applications in industry and engineering fields, mainly in crude oil extraction from petroleum manufacturing. The Carreau fluid is also a one of the non-Newtonian fluids. Carreau fluid model is substantial for gooey, high and low shear rates. On account of this headway, it has profited in numerous innovative and assembling streams. The effect of power-law index on unsteady stretching sheet was explained by Chen (2003) and Abbasbandy (2008). Recently, the researchers [Raju et al. (2016), Raju et al. (2016), Sandeep et al. (2016), Babu et al.(2016), Animasun et al. (2016), Sandeep et al.(2016)] studied the heat and mass transfer of MHD flows through different channels. The effect of cross diffusion on MHD bio convection flow over a horizontal surface were discussed by Makinde and Animasaun (2016). Makinde and Animasaun (2016) have presented the MHD nanofluid on bio convection flow of a paraboloid revolution with

\footnotetext{
* Corresponding Author.Email: dr.nsrh@gmail.com
} 
nonlinear thermal radiation and chemical reaction. Sandeep (2016), Ramana Reddy et al. (2017) and Ali et al. (2017) studied the heat transfer behaviour of MHD flows.

To the authors' knowledge no studies have been reported yet on flow and heat transfer of electrically conducting liquid film flow of Carreau nanofluid over a stretching sheet by considering the aligned magnetic field in the presence of space and temperature dependent heat source/sink, viscous dissipation and thermal radiation. For this study, we considered kerosene as the base fluid embedded with the silver (Ag) and copper $(\mathrm{Cu})$ nanoparticles. Numerical results are determined by employing Runge-Kutta and Newton's methods. Graphs are exhibited and explained for various parameters of interest. The influence of pertinent parameters on reduced Nusselt number, flow and heat transfer is discussed with the assistance of graphs and tables

\section{MATHEMATICAL FORMULATION}

Let us consider an unsteady, two-dimensional boundary layer flow of an electrically conducting and heat generating Carreau nanofluid over a stretching sheet bounded by a thin liquid film of uniform thickness $h(t)$ over a horizontal elastic sheet which emerges from a narrow slit at the origin of the cartesian coordinate system which is schematically represented in Fig.1. The sheet is stretched along the $x$-axis with stretching velocity $U(x, t)$ and $y$-axis is normal to it. An inclined magnetic field $B_{0}$ is applied to the stretching sheet at an angle $\gamma$. The effects of non-uniform heat source/sink, thermal radiation, viscous dissipation and volume fraction are taken into consideration. We assume that the surface temperature $T$ s of the stretching sheet varies with respect to distance $x$-from the slit as

$T_{s}=T_{0}-T_{r e f}\left(\frac{b x^{2}}{2 v_{f}}\right)(1-\alpha t)^{-\frac{3}{2}}$

$U(x, t)=b x /(1-\alpha t)$

The Eqn. (2) is for the sheet velocity $U(x, t)$ reflects that the elastic sheet, the elastic sheet is fixed at the origin and stretched by applying a force in the positive $x$-direction. We used $\alpha>0$ because the stretching rate $b /(1-\alpha t)$ increases with time. Similarly, Eqn. (2) represents the decrease in sheet temperature from $T_{0}$ at the slit in proportion to $x^{2}$.

The constitutive equations for a Carreau fluid is given by

$\bar{\tau}_{i j}=\eta_{0}\left[1+\frac{(n-1)}{2}(\Gamma \overline{\dot{\gamma}})^{2}\right] \overline{\dot{\gamma}}_{i j}$

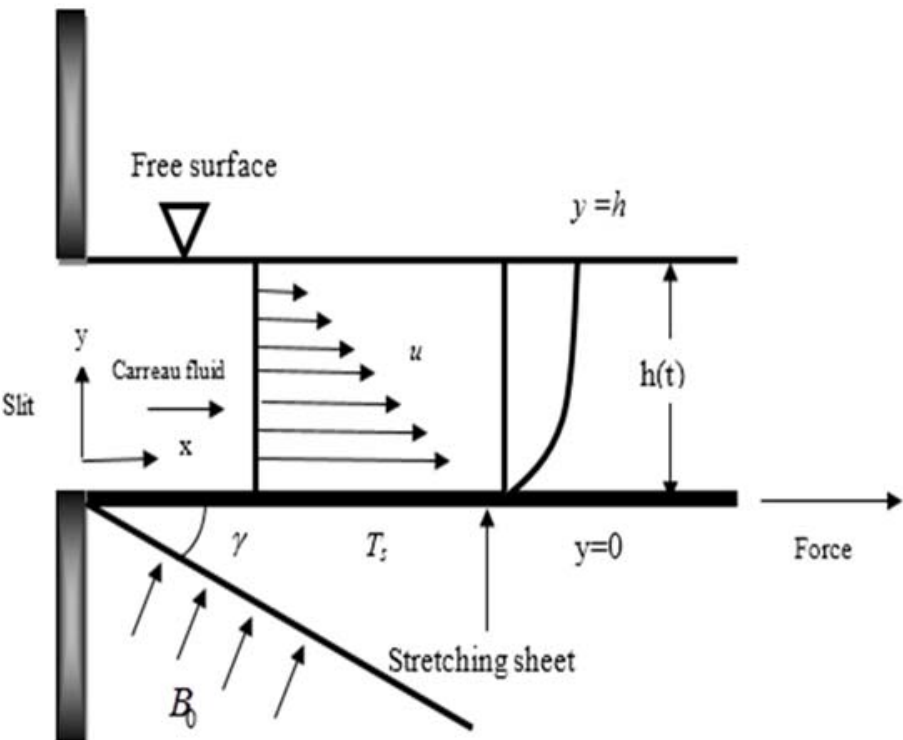

Fig. 1 Flow geomrtry of the problem
In which $\bar{\tau}_{i j}$ is the extra stress tensor, $\eta_{0}$ is the zero shear rate viscosity, $\Gamma$ is the time constant, $n$ is power-law index and $\overline{\dot{\gamma}}_{i j}$ is defined as

$\overline{\dot{\gamma}}=\sqrt{\frac{1}{2} \sum_{i} \sum_{j} \overline{\dot{\gamma}}_{i j} \overline{\dot{\gamma}}_{j i}}=\sqrt{\frac{1}{2}} \Pi$.

Here $\Pi$ is the second invariant strain tensor.

The governing boundary layer equations for momentum and thermal energy with associated boundary conditions are

$\frac{\partial u}{\partial x}+\frac{\partial v}{\partial y}=0$

$\rho_{n f}\left(\frac{\partial u}{\partial t}+u \frac{\partial u}{\partial x}+v \frac{\partial u}{\partial y}\right)$

$=\mu_{n f}\left(1+\frac{3(n-1) \Gamma^{2}}{2}\left(\frac{\partial u}{\partial y}\right)^{2}\right) \frac{\partial^{2} u}{\partial y^{2}}-\sigma B_{0}^{2} \cos ^{2} \gamma u$,

$\left(\rho c_{p}\right)_{n f}\left(\frac{\partial T}{\partial t}+u \frac{\partial T}{\partial x}+v \frac{\partial T}{\partial y}\right)$

$$
=k_{n f} \frac{\partial^{2} T}{\partial y^{2}}+\mu_{n f}\left(\frac{\partial u}{\partial y}\right)^{2}+q^{\prime \prime},
$$

$u=U_{w}, \quad v=0, \quad T=T_{s}$ at $\mathrm{y}=0$,

$\frac{\partial u}{\partial y}=0, \quad \frac{\partial T}{\partial y}=0$, at $\mathrm{y}=\mathrm{h}$,

$v=\frac{d h}{d t} \quad$ as $y=h(t)$,

where

$\left.\begin{array}{l}\rho_{n f}=(1-\phi) \rho_{f}+\phi \rho_{s}, \quad \mu_{n f}=\frac{\mu_{f}}{(1-\phi)^{2.5}}, \\ k_{n f}=k_{f}\left[\frac{k_{s}+2 k_{f}-2 \phi\left(k_{f}-k_{s}\right)}{k_{s}+2 k_{f}+\phi\left(k_{f}-k_{s}\right)}\right] \\ \left(\rho c_{p}\right)_{n f}=(1-\phi)\left(\rho c_{p}\right)_{f}+\phi\left(\rho c_{p}\right)_{s}\end{array}\right\}$,

The non-uniform heat generation/absorption $q^{\prime \prime}$ is taken as

$q^{\prime \prime}=\frac{k_{f} U_{w}}{x v_{f}}\left[A^{*}\left(T_{s}-T_{0}\right) f^{\prime}+B^{*}\left(T-T_{0}\right)\right]$,

Let us now introduce the similarity variables as given below

$$
\begin{aligned}
& u=\frac{b x}{(1-\alpha t)} f^{\prime}(\eta) \text {, } \\
& v=-\left(b v_{f}\right)^{-\frac{1}{2}}(1-\alpha t)^{-\frac{1}{2}} f(\eta) \text {, } \\
& \eta=\left(b / v_{f}\right)^{\frac{1}{2}}(1-\alpha t)^{-\frac{1}{2}} y \text {, } \\
& T=T_{0}-T_{r e f}\left(b x^{2} / 2 v_{f}\right)(1-\alpha t)^{-\frac{3}{2}} \theta(\eta),
\end{aligned}
$$

Now by using Eqs. (6)- (11), the Eqs. (6)- (8) transformed as

$$
\begin{aligned}
& f^{\prime \prime}\left(1+\frac{3(n-1)}{2} W_{e} f^{\prime 2}\right) \\
& +B_{1}\left\{B_{2}\left(S\left(f^{\prime}+\frac{\eta}{2} f^{\prime \prime}\right)+f f^{\prime \prime}-f^{\prime 2}\right)-M \cos ^{2} \gamma f^{\prime}\right\}=0 \\
& B_{3} \theta^{\prime \prime}+\frac{E c \operatorname{Pr}}{B_{1}} f^{\prime 2}+\left(A^{*} f^{\prime}+B^{*} \theta\right) \\
& -B_{4} \operatorname{Pr}\left(\frac{S}{2}\left(\eta \theta^{\prime}+3 \theta\right)+2 f^{\prime} \theta-f \theta^{\prime}\right)=0
\end{aligned}
$$


where,

$$
\begin{aligned}
& B_{1}=(1-\phi)^{2.5}, \quad B_{2}=1-\phi+\phi \frac{\rho_{s}}{\rho_{f}}, \\
& B_{3}=\frac{k_{n f}}{k_{f}}, \quad B_{4}=1-\phi+\phi \frac{\left(\rho c_{p}\right)_{s}}{\left(\rho c_{p}\right)_{f}},
\end{aligned}
$$

Corresponding boundary conditions are

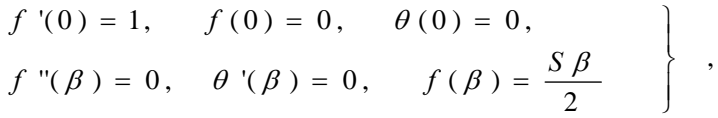

here $S=\alpha / b$ is unsteadiness parameter and prime represents differentiation with respect to $\eta$. Further, $\beta$ indicates the value of the similarity variable $\eta$ at the free surface so that $\eta$ value gives

$\beta=\left(\frac{b}{v_{f}(1-\alpha t)}\right)^{\frac{1}{2}} h$,

The rate at which film thickness varies can be obtained by differentiating (16) w.r.t,

$\frac{d h}{d t}=-\frac{\alpha \beta}{2}\left(\frac{v_{f}}{b(1-\alpha t)}\right)^{\frac{1}{2}}$,

where

$\operatorname{Pr}=\left(\mu c_{p}\right)_{f} / k_{f}, W e^{2}=\frac{b^{3} x^{2} \Gamma^{2}}{v_{f}(1-\alpha t)^{3}}$,

$M=\frac{\sigma B_{0}^{2}}{\rho_{f} b}, R=\frac{4 \sigma^{*} T_{0}^{3}}{k^{*} k_{f}}, S=\frac{\alpha}{b}, E c=\frac{U_{w}^{2}}{c_{p}\left(T_{s}-T_{0}\right)}$,

The physical quantities of practical interest in this problem are the skin friction coefficient $C_{f}$ and the Nusselt number $N u$, which are given as

$C_{f}=\frac{\tau_{w}}{\rho_{f} U_{w}^{2}}, \quad N u=\frac{q_{w} x}{k_{f}\left(T_{s}-T_{0}\right)}$,

where,

$$
\tau_{w}=\mu_{n f}\left(\frac{\partial u}{\partial y}\right)_{y=0}, \quad q_{w}=-\frac{k_{n f}}{k_{f}}\left(\frac{\partial T}{\partial y}\right)_{y=0},
$$

Substituting Eqn. (19) in Eqn. (20), we obtain

$$
B_{1} C_{f x} \mathrm{Re}_{x}^{-1 / 2}=f^{\prime \prime}(0), \quad\left(1 / B_{3}\right) N u_{x} \mathrm{Re}_{x}^{1 / 2}=-\theta^{\prime}(0)
$$

where, $\mathrm{R}_{x}=U_{w} x / v_{f}$ is the local Reynolds number.

\section{RESULTS AND DISCUSSION}

Eqs. (15) and (16), subject to the boundary conditions Eq. (18) are solved numerically using Runge-Kutta and Newton's methods. The influence of pertinent parameters namely, magnetic field parameter, unsteadiness parameter, heat source/sink parameter, Eckert number, volume fraction of nanoparticles etc. on the flow and heat transfer of the thin film flow are discussed. For numerical computations, we considered the nondimensional parameter values as $S=W e=0.5, \gamma=\pi / 4$,

$A^{*}=B^{*}=0.2, M=2, \cdot n=1.5, E c=0.1$. These values are kept as common in entire study except the variations in the respective figures.

Figs. 2 and 3 explain the effect of $M$ on the velocity and temperature fields respectively. It is observed that increasing values of $M$ declines the velocity field and enhances the temperature field.

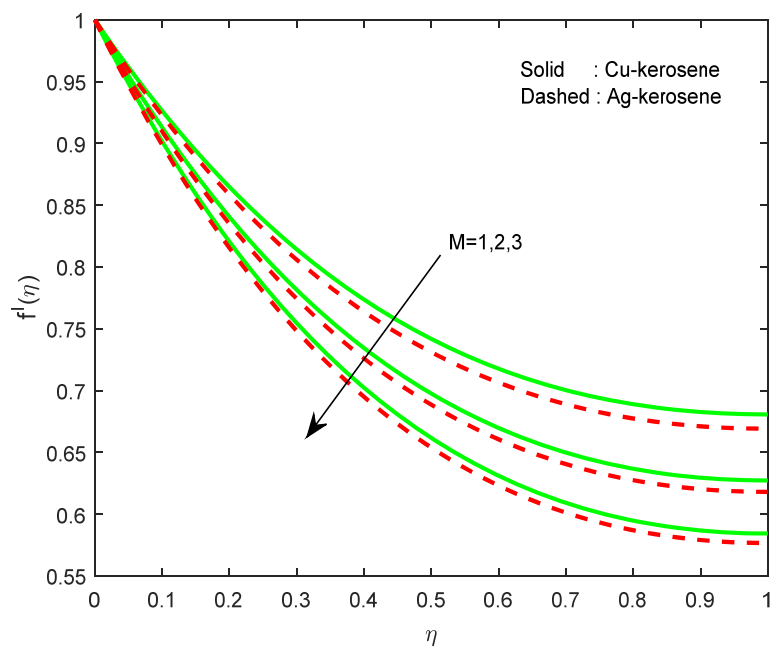

Fig. 2 Velocity profile for different values of $M$

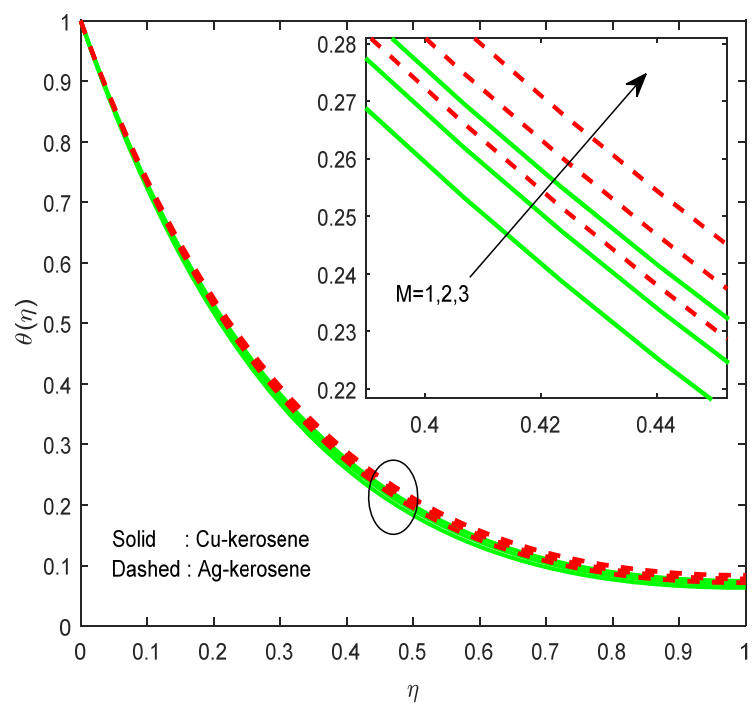

Fig. 3 Temperature profile for different values of $M$

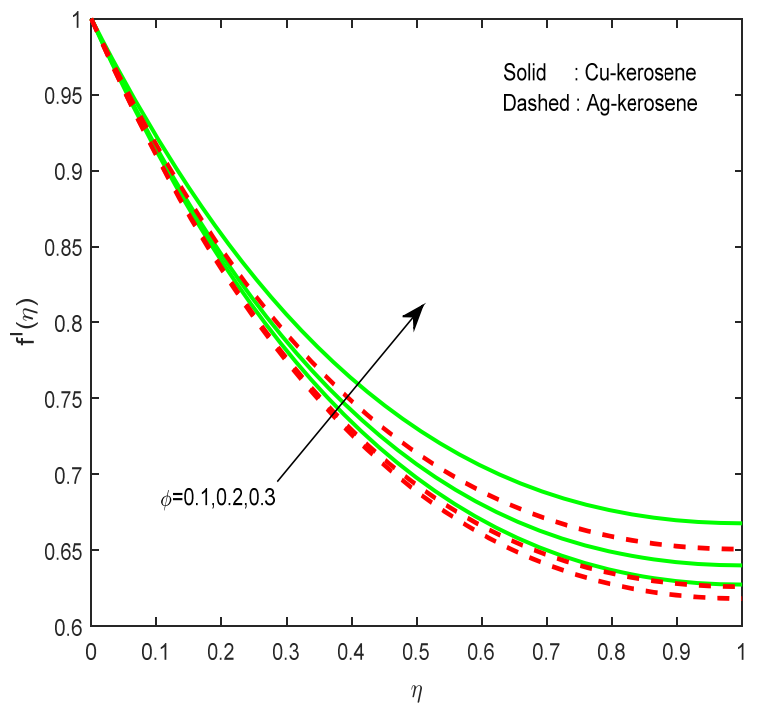

Fig. 4 Velocity profile for different values of $\phi$ 


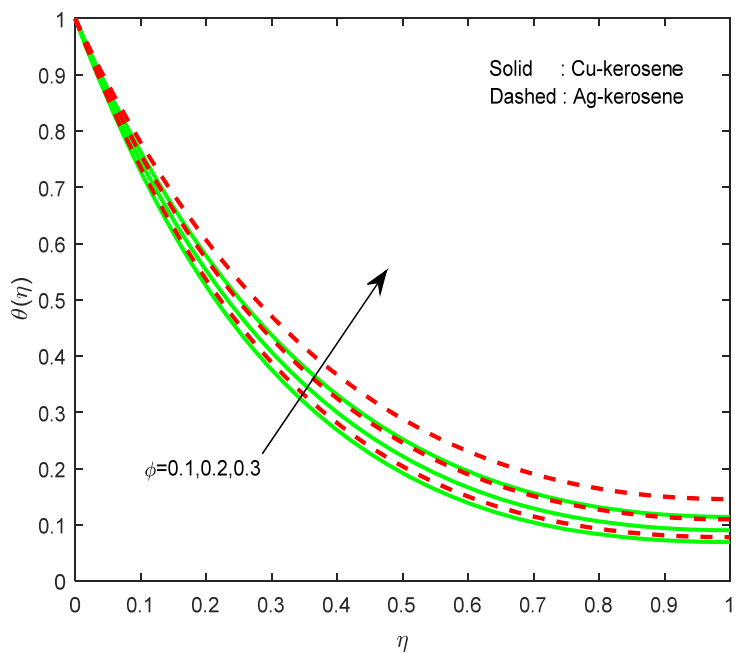

Fig. 5 Temperature profile for different values of $\phi$

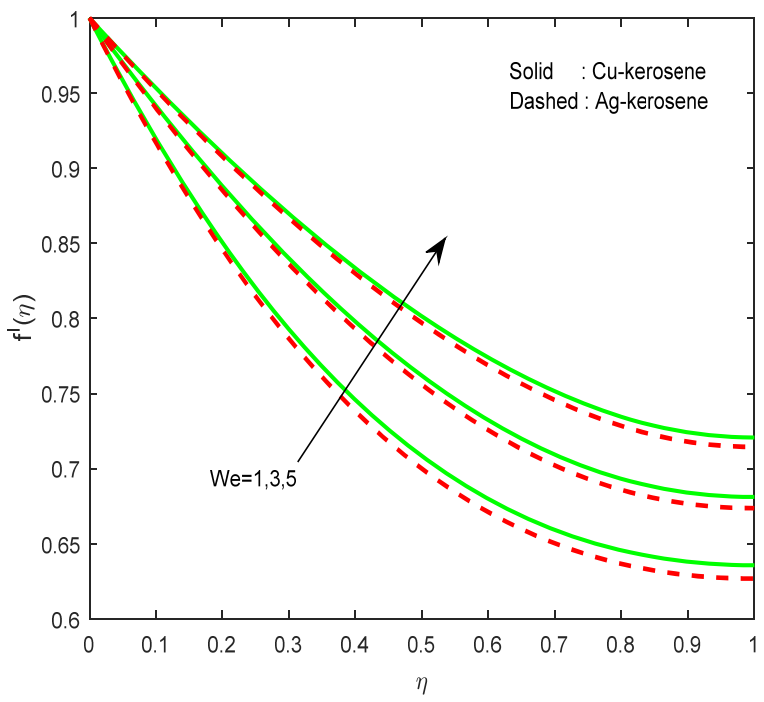

Fig. 6 Velocity profile for different values of $W e$

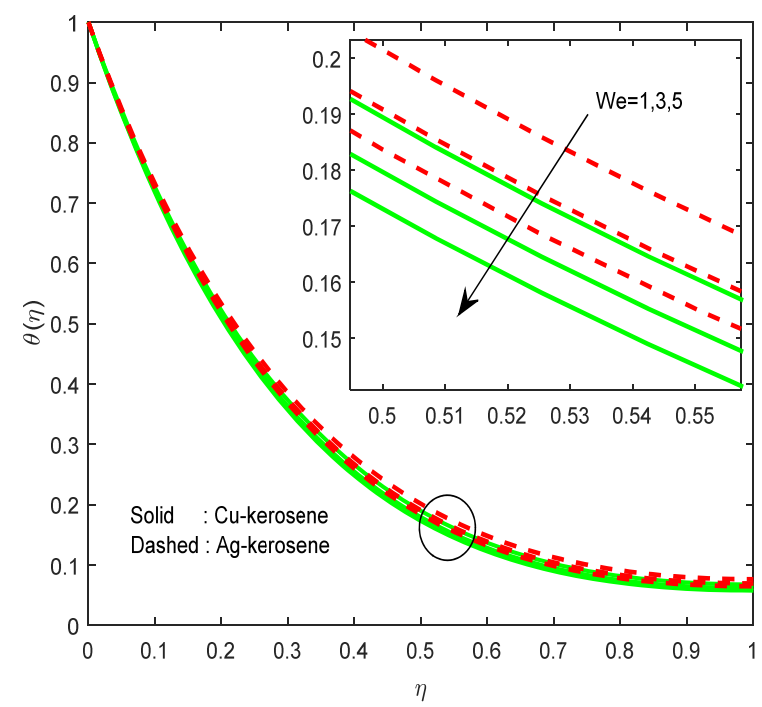

Fig. 7 Temperature profile for different values of $W e$

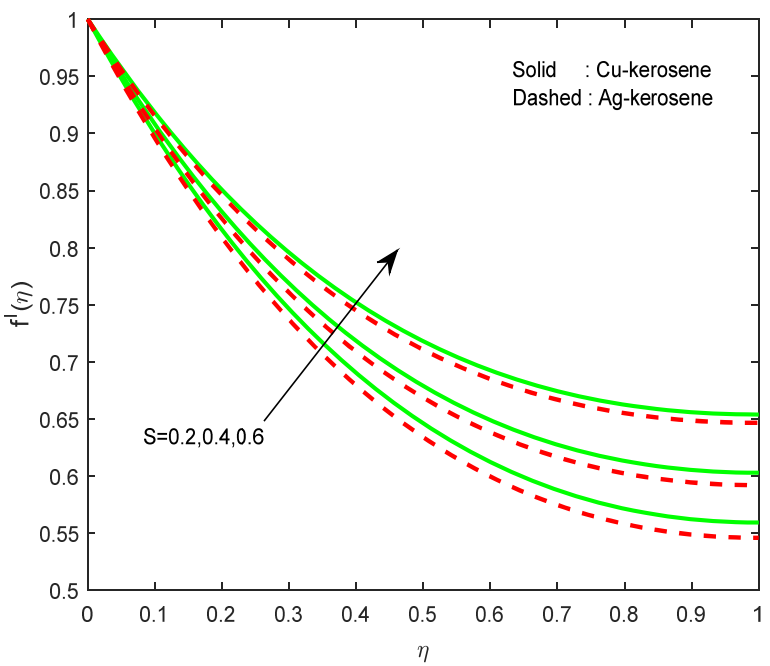

Fig. 8 Velocity profile for different values of $S$

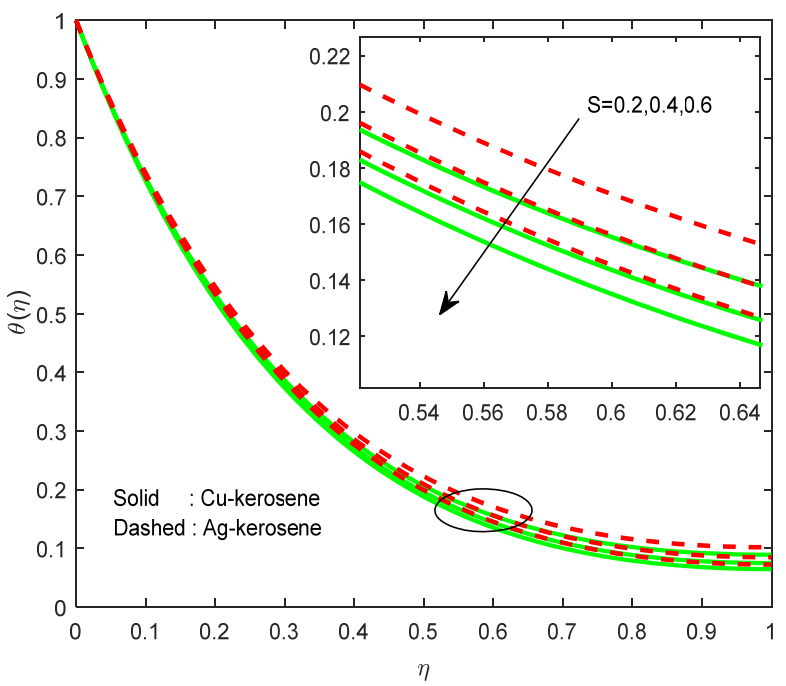

Fig. 9 Temperature profile for different values of $S$

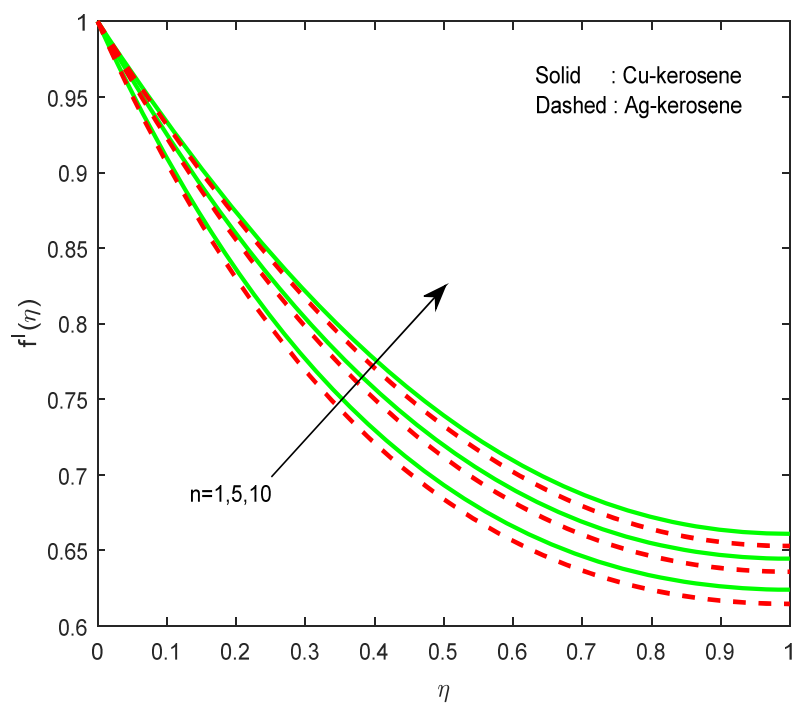

Fig. 10 Velocity profile for different values of $n$ 


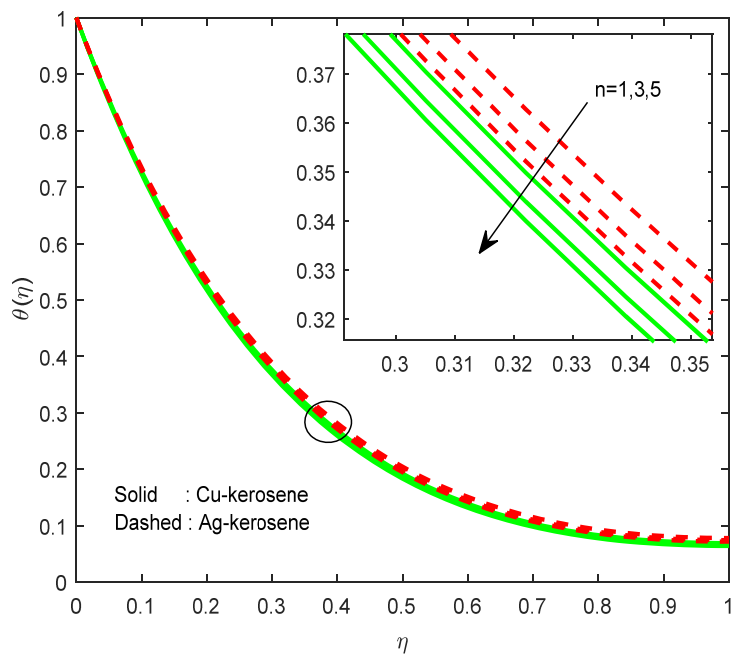

Fig. 11 Temperature profile for different values of $n$

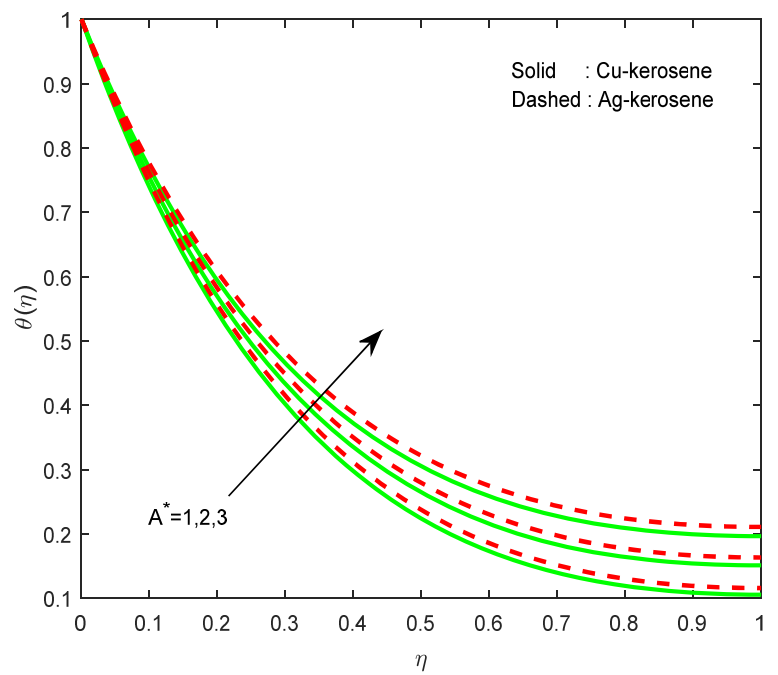

Fig. 12 Temperature profile for different values of $A$ *

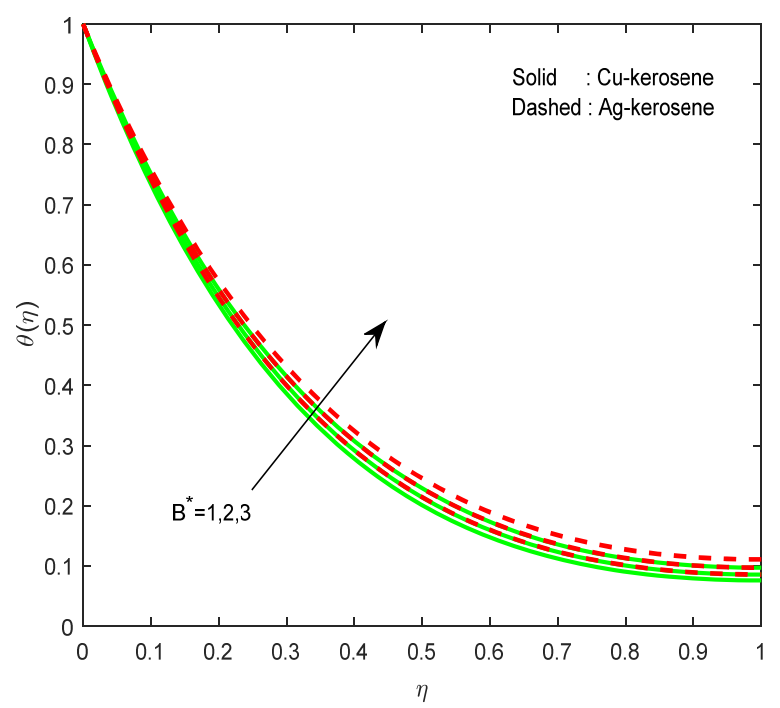

Fig. 13 Temperature profile for different values of $B$ *

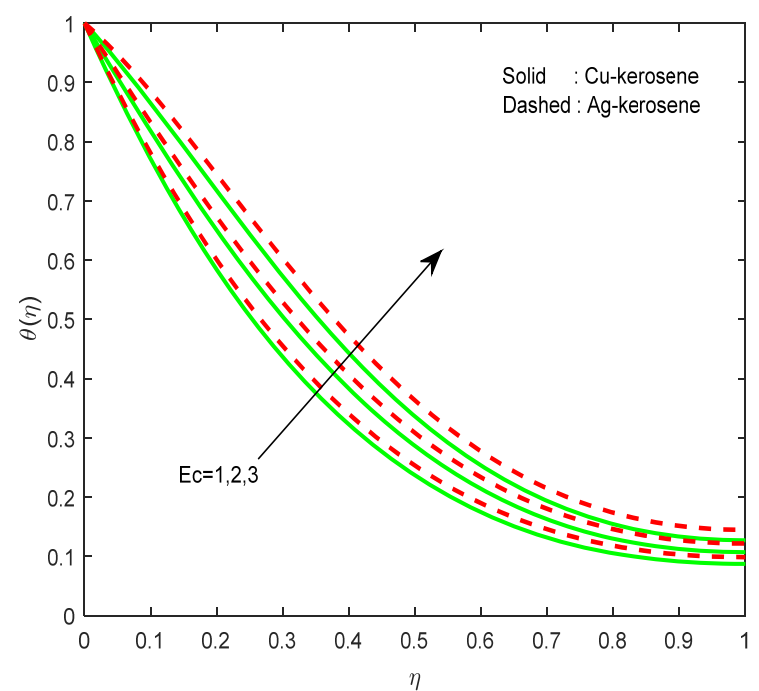

Fig. 14 Temperature profile for different value of $E c$

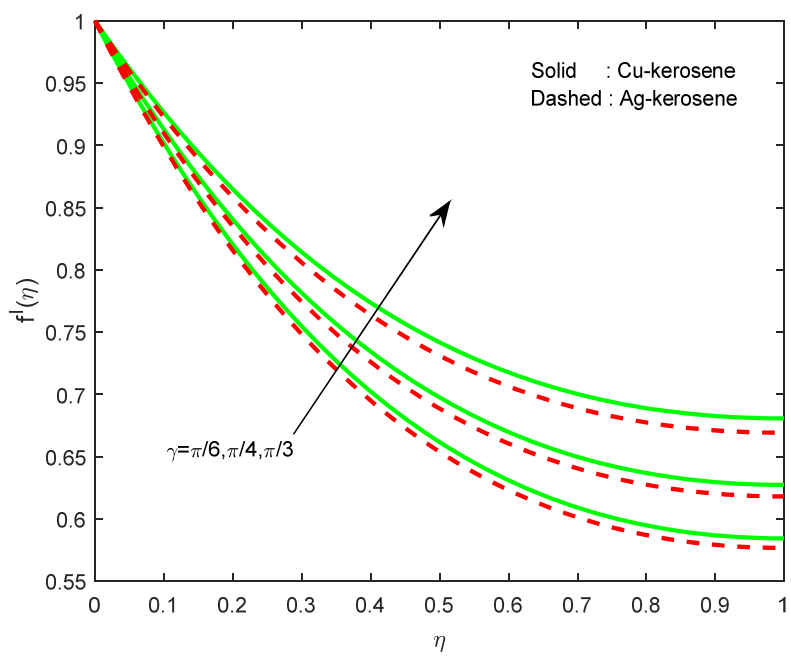

Fig. 15 Temperature profile for different value of $\gamma$

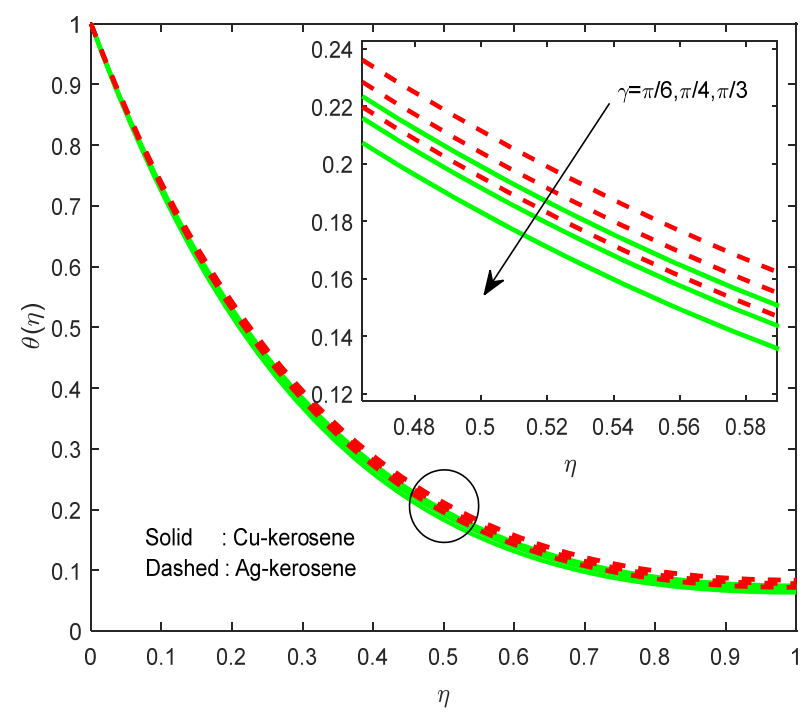

Fig. 16 Temperature profile for different value of $\gamma$ 
Table 1 Physical parameter values of $f^{\prime \prime}(0)$ and $-\theta^{\prime}(0)$ for $\mathrm{Cu}-$ kerosene nanofluid

\begin{tabular}{|c|c|c|c|c|c|c|c|c|c|}
\hline$M$ & $\phi$ & $W e$ & $S$ & $n$ & $A^{*}$ & $E$ & $\gamma^{0}$ & $f^{\prime \prime}(0)$ & $-\theta$ \\
\hline 1 & & & & & & & & -0.800673 & 3.183502 \\
\hline 2 & & & & & & & & -0.951051 & 3.137925 \\
\hline 3 & & & & & & & & -1.077238 & 3.097322 \\
\hline & .1 & & & & & & & -0.951051 & 3.137925 \\
\hline & .2 & & & & & & & -0.926769 & 2.900338 \\
\hline & .3 & & & & & & & -0.843920 & 2.683437 \\
\hline & & 1 & & & & & & -0.865479 & 3.155764 \\
\hline & & 3 & & & & & & -0.611938 & 3.218581 \\
\hline & & 5 & & & & & & -0.484571 & 3.252867 \\
\hline & & & .2 & & & & & -1.090240 & 3.094797 \\
\hline & & & .4 & & & & & -1.002314 & 3.125135 \\
\hline & & & .6 & & & & & -0.894041 & 3.149859 \\
\hline & & & & 1 & & & & -0.995049 & 3.129665 \\
\hline & & & & 5 & & & & -0.796797 & 3.171534 \\
\hline & & & & 10 & & & & -0.700307 & 3.195477 \\
\hline & & & & & 1 & & & -0.951051 & 3.002623 \\
\hline & & & & & 2 & & & -0.951051 & 2.833496 \\
\hline & & & & & 3 & & & -0.951051 & 2.664369 \\
\hline & & & & & & 1 & & -0.951051 & 2.534955 \\
\hline & & & & & & 2 & & -0.951051 & 1.864989 \\
\hline & & & & & & 3 & & -0.951051 & 1.195023 \\
\hline & & & & & & & 30 & -1.077238 & 3.097322 \\
\hline & & & & & & & 45 & -0.951051 & 3.137925 \\
\hline & & & & & & & 60 & -0.800673 & 3.183502 \\
\hline
\end{tabular}

Generally, introducing the transverse magnetic field create a drag force due to the Lorentz force and hence the result retarding the velocity field. The effects of $\phi$ on the velocity and temperature profiles are depicted in Figs. 4 and 5, respectively. The result shows that as the solid volume fraction of the film increases both the velocity and temperature field increases. This is due to the fact that increasing in volume fraction of nano particle enhances the thermal conductivity of the flow. Figs. 6 and 7 demonstrate the influence of $W e$ on the velocity and temperature profiles. It is observed that the velocity increases for increasing values of $W e$ and opposite trend has been observed in temperature field. Physically, higher value of $W e$ will depreciate the viscosity forces of the Carreau fluid.

Figs. 8 and 9 illustrate the influence of unsteadiness parameter on velocity and temperature profiles respectively. It is observed that increasing values of $S$ boosts the velocity field and declines the temperature field. Generally, unsteadiness parameter $S$ is controlled by both $\alpha$ and $b$, increasing the value of unsteadiness parameter increases the heat loose by the thin film. Due to this reason we have seen a fall in the temperature field. Figs. 10 and 11 represent the effect of power law index on velocity and temperature fields. We noticed an enhancement in the velocity profile and depreciate the temperature profile. Physically, increase in the power law index made to thicken the liquid film associated with an enhancement of the thermal boundary layer.

Fig.12 and 13 display the influence of non-uniform heat source/sink parameter on the temperature field. It is observed that increasing the nonuniform heat source/sink parameter enhances the temperature fields. The effect of Eckert number on temperature profile is shown in Fig.14. We obtain that increasing values of Eckert number enhance the temperature profiles. Due to the fact that heat energy is saved in the liquid due to the frictional heating. The influence of aligned angle on velocity and temperature profiles is presented in Figs. 15 and 16. We obtained an interesting result that the enhancement in the value of aligned parameter increases the velocity field and depreciate the temperature field.

Table- 1 and 2 show the effect of physical parameters on friction factor and local Nusselt number for $\mathrm{Cu}$-kerosene and Ag- Kerosene nanofluids. It is evident from the tables that increasing values of the magnetic field parameter reduce friction factor and heat transfer rate. A rise in the value of volume fraction of nanoparticles enhances the friction factor and declines the heat transfer rate. An increase in the value of aligned angle parameter enhances both friction factor and heat transfer rate. Weissenberg and unsteadiness parameters have tendency to enhance the heat transfer rate.

Table 2 Physical parameter values of $f$ "(0) and $-\theta$ '(0) for Agkerosene nanofluid

\begin{tabular}{|l|l|l|l|l|l|l|l|l|l|}
\hline$M$ & $\phi$ & $W e$ & $S$ & $n$ & $A$ & $E c$ & $\gamma^{0}$ & $f^{\prime \prime}(0)$ & $-\theta{ }^{\prime}(0)$ \\
\hline 1 & & & & & & & & -0.841593 & 3.090642 \\
\hline 2 & & & & & & & & -0.987394 & 3.045404 \\
\hline 3 & & & & & & & & -1.110328 & 3.005010 \\
\hline & .1 & & & & & & & -0.987394 & 3.045404 \\
\hline & .2 & & & & & & & -0.982125 & 2.739717 \\
\hline & .3 & & & & & & & -0.907088 & 2.473053 \\
\hline & & 1 & & & & & & -0.894219 & 3.064925 \\
\hline & & 3 & & & & & & -0.627126 & 3.132014 \\
\hline & & 5 & & & & & & -0.495591 & 3.168031 \\
\hline & & & .2 & & & & & -1.133904 & 2.982102 \\
\hline & & & .4 & & & & & -1.041797 & 3.026448 \\
\hline & & & .6 & & & & & -0.926340 & 3.063119 \\
\hline & & & & 1 & & & & -1.036497 & 3.036220 \\
\hline & & & & 5 & & & & -0.820912 & 3.081939 \\
\hline & & & & 10 & & & & -0.719234 & 3.107549 \\
\hline & & & & & 1 & & & -0.987394 & 2.906601 \\
\hline & & & & & 2 & & & -0.987394 & 2.733098 \\
\hline & & & & & 3 & & & -0.987394 & 2.559594 \\
\hline & & & & & & 1 & & -0.987395 & 2.390294 \\
\hline & & & & & & 2 & & -0.987395 & 1.662395 \\
\hline & & & & & & 3 & & -0.987395 & 0.934497 \\
\hline & & & & & & & 30 & -1.110328 & 3.005010 \\
\hline & & & & & & & 45 & -0.987394 & 3.045404 \\
\hline & & & & & & & 60 & -0.841593 & 3.090642 \\
\hline
\end{tabular}

\section{CONCLUSIONS}

This study presents the flow and heat transfer of electrically conducting liquid film flow of Carreau nanofluid over a stretching sheet by considering the aligned magnetic field in the presence of space and temperature dependent heat source/sink and viscous dissipation. For this study, we considered kerosene as the base fluid embedded with the silver (Ag) and copper $(\mathrm{Cu})$ nanoparticles. Numerical results are determined by employing Runge-Kutta and Newton's methods. Graphs are exhibited and explained for various parameters of interest. The conclusions of the present study are as follows:

- Increasing in power-law index and unsteadiness parameter enhances the heat transfer rate.

- Magnetic field parameter have tendency to reduce skin friction coefficient and local Nusselt number.

- $\quad$ Rise in the Weissenberg number depreciate the friction factor and increases the heat transfer rate.

- An increase in aligned angle enhances the skin friction coefficient and local Nusselt number.

- $\quad$ Temperature field of Ag-kerosene nanofluid is effective when compared with the temperature field of $\mathrm{Cu}$-kerosene nanofluid. 


\section{REFERENCES}

Abbasbandy, S., Yurusoy, M. and Pakdemirli, M., 2008, “The Analysis Approach of Boundary Layer Equation of Power-Law Fluids of Second Grade,” Zzeitschrift fur Naturforschung A, 63, 564-570.

http://dx.doi.org/10.1515/zna-2008-0906

Abdel-Rahman, G.M., 2011, "Effect of Magnetohydrodynamic on Thin Films of Unsteady Micropolar Fluid through A Porous Medium,” J. Mod. Phys., 2, 1290-1304.

http://dx.doi.org/10.4236/jmp.2011.211160

Ali, M.E., Sandeep, N., 2017, “Cattaneo-Christov Model for Radiative Heat Transfer of Magnetohydrodynamic Casson-Ferrofluid: A Numerical Study,” Results in Physics, 7, 21-30.

http://dx.doi.org/10.1016/j.rinp.2016.11.055

Andersson, H.I., Aarseth, J.B., Braud, N. and Dandapat, B.S., 1996, "Flow Of A Power-Law Fluid on an Unsteady Stretching Surface," $J$. Non-Newtonian Fluid Mech., 62, 1-8. http://dx.doi.org/10.1016/0377-0257(95)01392-X

Anderson, H. I., Bech, K.H., and Dandapat, B.S., 1992, "Magneto Hydrodynamics Flow Of A Power-Law Fluid Over A Stretching Sheet," Int. J. Non-Linear Mech., 27, 929-936. http://dx.doi.org/10.1016/0020-7462(92)90045-9

Animasun, I.L., Raju, C.S.K. and Sandeep, N., 2016, "Unequal Diffusivities Case of Homogeneous-Heterogeneous Reactions within Viscoelastic Fluid Flow in the Presence of Induced Magnetic Field and Nonlinear Thermal Radiation,” Alexandria Engineering Journal, 55(2), 1595-1606. http://dx.doi.org/10.1016/j.aej.2016.01.018.

Aziz, R.C., Hashim, I. and Abbasbandy, S., 2012, "Effects of Thermocapillarity and Thermal Radiation on Flow and Heat Transfer In A Thin Liquid Film on an Unsteady Stretching Sheet," Math. Probl. Eng., 2012.

Babu, M.J., Sandeep, N. and Raju, C.S.K., 2016, "Heat and Mass Transfer in MHD Eyring-Powell Nanofluid Flow Due To Cone in Porous Medium," International Journal of Engineering Research in Africa, 19, 57-74.

http://dx.doi.org/10.4028/www.scientific.net/JERA.19.57

Chen, C.H., 2003, "Heat Transfer in A Power-Law Fluid Film Over an Unsteady Stretching Sheet," Heat Mass Transf. Und Stoffuebertragung. 39, 791-796.

http://dx.doi.org/10.1007/s00231-002-0363-2

Chen, C.H., 2006, "Effect of Viscous Dissipation on Heat Transfer in A Non-Newtonian Liquid Film over an Unsteady Stretching Sheet," $J$. Nonnewton. Fluid Mech. 135, 128-135. http://dx.doi.org/10.1016/j.jnnfm.2006.01.009.

Chen, C.H., 2003, "Heat Transfer in a Power-Law Fluid Film over an Unsteady Stretching Sheet," Heat Mass Transfer, 39, 791-796.

http://dx.doi.org/10.1007/s00231-002-0363-2

Dandapat, B.S., Maity, S. and Kitamura, A., 2008, "Liquid Film Flow Due To an Unsteady Stretching Sheet,” Int. J. Non. Linear. Mech. 43, 880-886.

http://dx.doi.org/10.1016/j.ijnonlinmec.2008.06.003

Dandapat, B.S., Santra, B. and Vejravelu, K., 2007, “The Effects Of Variable Fluid Properties And The Thermo Capillarity On The Flow Of
A Thin Film On Stretching Sheet,” Int. J. Heat and Mass transfer, 50, 991-996.

http://dx.doi.org/10.1016/j.ijheatmasstransfer.2006.08.007

Dandapat, B.S., Santra, B. and Andersson, H.I., 2003, "Thermo Capillarity in a Liquid Film on an Unsteady Stretching Surface," Int. J. Heat and Mass transfer, 46, 3009-3015. http://dx.doi.org/10.1016/S0017-9310(03)00078-4

Dandapat, B.S. and Chakraborty, S., 2010, "Effects of Variable Fluid Properties on Unsteady Thin-Film Flow over a Non-Linear Stretching Sheet,” Int. J. Heat Mass Transf., 53, 5757-5763. http://dx.doi.org/10.1016/j.ijheatmasstransfer.2010.08.007

Dandapat, B.S. and Singh, S.K., 2011, “Thin Film Flow over a Heated Nonlinear Stretching Sheet in Presence of Uniform Transverse Magnetic Field," Int. Commun. Heat Mass Transf., 38, 324-328.

http://dx.doi.org/10.1016/j.icheatmasstransfer.2010.11.009

Khader, M.M., and Megahed, A.M., 2013, “Numerical Simulation Using The Finite Difference Method for the Flow and Heat Transfer in a Thin Liquid Film over an Unsteady Stretching Sheet in a Saturated Porous Medium in the Presence of Thermal Radiation," J. King Saud Univ. Eng. Sci., 25, 29-34.

http://dx.doi.org/10.1016/j.jksues.2011.10.002

Khan, Y., Wu, Q., Faraz, N., and Yildirim, A., 2011, "The Effects of Variable Viscosity and Thermal Conductivity on a Thin Film Flow over a Shrinking/Stretching Sheet,” Comput. Math. with Appl., 61, 33913399.

http://dx.doi.org/10.1016/j.camwa.2011.04.053

Liu, I.C. and Megahed, A.M., 2012, “Homotopy Perturbation Method for Thin Film Flow and Heat Transfer over an Unsteady Stretching Sheet with Internal Heating and Variable Heat Flux," J. Appl. Math., http://dx.doi.org/10.1155/2012/418527

Liu, I.C., Megahed, A. and Wang, H.H., 2013, "Heat Transfer in a Liquid Film due to an Unsteady Stretching Surface with Variable Heat Flux,” $J$. Appl. Mech., 80, 1-7.

http://dx.doi.org/10.1115/1.4007966

Lin, Y., Zheng, L., Zhang, X., Ma, L. and Chen, G., 2015, “MHD Pseudo-Plastic Nanofluid Unsteady Flow And Heat Transfer In A Finite Thin Film Over Stretching Surface With Internal Heat Generation,” Int. J. Heat Mass Transf. , 84, 903-911.

http://dx.doi.org/10.1016/j.ijheatmasstransfer.2015.01.099

Makinde, O.D., and Animasaun, I. L., (2016), “Thermophoresis and Brownian Motion Effect on MHD Bioconvection of Nanofluid with Nonlinear Thermal Radiation and Quartic Chemical Reaction Past an Upper Horizontal Surface of A Paraboloid of Revolution,” J. of Mole. Liquids, 221, 733-743.

http://dx.doi.org/10.1016/j.molliq.2016.06.047

Makinde, O.D., and Animasaun, I. L., (2016), "Bioconvection in MHD Nanofluid Flow with Nonlinear Thermal Radiation and Quartic Autocatalysis Chemical Reaction Past an Upper Surface of A Paraboloid Of Revolution,” J. of Ther. Sci., 109, 159-171.

http://dx.doi.org/10.1016/j.ijthermalsci.2016.06.003

Noor, N.F.M. and Hashim, I., 2010, "Thermocapillarity and Magnetic Field Effects in a Thin Liquid Film on an Unsteady Stretching Surface,” Int. J. Heat and mass Transfer, 53, 2044-2051.

http://dx.doi.org/10.1016/j.ijheatmasstransfer.2009.12.052 
Raju, C.S.K. and Sandeep, N., 2016, "Heat and Mass Transfer in MHD Non-Newtonian Bio-Convection Flow over a Rotating Cone/Plate with Cross Diffusion,” Journal of Molecular Liquids, 215, 115-126. http://dx.doi.org/10.1016/j.molliq.2015.12.058

Raju, C.S.K., Sandeep, N. and Malvandi, A., 2016, "Free Convective Heat and Mass Transfer of MHD Non-Newtonian Nanofluids over a Cone in the Presence of Non-Uniform Heat Source/Sink," J. Molecular Liquids, 221, 101-115.

http://dx.doi.org/10.1016/j.molliq.2016.05.078

Raju, C.S.K., Sandeep, N. and Sugunamma, V., 2016, “Dual Solutions For Three-Dimensional MHD Flow Of A Nanofluid Over A Nonlinearly Permeable Stretching Sheet," Alexandria Engineering Journal, 55, 151162.

http://dx.doi.org/10.1016/j.aej.2015.12.017

Ramana Reddy, J.V. , Sugunamma, V. , Sandeep, N. , 2017, “Effect Of Frictional Heating on Radiative Ferrofluid Flow over a Slendering Stretching Sheet With Aligned Magnetic Field,” Europen Physical Journal Plus, 132:7

http://doi:10.1140/epjp/i2017-11287-1

Sajid, M., Ali, N. and Hayat, T., 2009, “On Exact Solutions for Thin Film Flows of A Micropolar Fluid,” Commun. Nonlinear Sci. Numer. Simul. 14, 451-461.

http://dx.doi.org/10.1016/j.cnsns.2007.09.003

Sajid, M., Hayat, T. and Asghar, S., 2007, “Comparison between the Ham and Hpm Solutions of Thin Film Flows Of Non-Newtonian Fluids on A Moving Belt,” Nonlinear Dyn. 50, 27-35. http://dx.doi.org/10.1007/s11071-006-9140-y.

Sandeep, N., Koriko, O.K. and Animasaun, I.L., 2016, "Modified Kinematic Viscosity Model for 3D-Casson Fluid Flow within Boundary
Layer Formed On A Surface At Absolute Zero,” Journal of Molecular Liquids.

http://dx.doi.org/10.1016/j.molliq.2016.06.049

Sandeep, N., Sulochana, C. and Animasaun, I.L., 2016, "StagnationPoint Flow of a Jeffrey Nano Fluid over a Stretching Surface with Induced Magnetic Field and Chemical Reaction,” Int. J. Eng. Research in Afrika, 20, 93-111.

http://dx.doi.org/10.4028/www.scientific.net/JERA.20.93

Sandeep, N., 2016, "Effect of Aligned Magnetic Field on Liquid Thin Film Flow of Magnetic-Nanofluid Embedded With Graphene Nanoparticles," Advanced Powder Technology, (in Press). http://dx.doi.org/10.1016/j.apt.2016.12.012

Santra, B. and Dandapat, B.S, 2008, "Unsteady Thin Film Flow Over A Heated Stretching Sheet,” Int. J. Heat. Mass transfer, 52, 1965-1970. http://dx.doi.org/10.1016/j.ijheatmasstransfer.2008.09.036

Tawade, J., Abel, M.S., Metri, P.G. and Koti, A., 2016, “Thin Film Flow and Heat Transfer Over an Unsteady Stretching Sheet with Thermal Radiation, Internal Heating In Presence of External Magnetic Field,” Int. Adv. Appl. Math. And Mech., 3, 29-40.

https://arxiv.org/abs/1603.03664

Vajravelu, K., Prasad, K. V. and Ng, C.O., 2012, “Unsteady Flow and Heat Transfer in a Thin Film of Ostwald-De Waele Liquid Over A Stretching Surface,” Commun. Nonlinear Sci. Numer. Simul. , 17, 41634173.

http://dx.doi.org/10.1016/j.cnsns.2012.01.027

Wang, C., 2006, “Analytic Solutions for A Liquid Film on an Unsteady Stretching Surface," Heat Mass Transf. Und Stoffuebertragung. 42, 759766.

http://dx.doi.org/10.1007/s00231-005-0027-0. 